\title{
Sterilization and extraction of palm oil from screw pressed palm fruit fiber using supercritical carbon dioxide
}

\begin{abstract}
The supercritical carbon dioxide (SC-CO2) was successfully used in the complete sterilization as well as simultaneous extraction of oil from screw pressed palm fruit fiber. The studies were conducted at different temperatures $\left(40,50,70{ }^{\circ} \mathrm{C}\right)$ and pressures $(13.7,20.7$ $\mathrm{MPa}$ ) for $60 \mathrm{~min}$ of extraction period. The bacteria, gram negative (Bacillus), present in the sample was completely killed at $20.7 \mathrm{MPa}$ and $50{ }^{\circ} \mathrm{C}$. Palmitic and oleic acid were found to be the major fatty acids in extracted oil. More saturated fatty acid were extracted at $50{ }^{\circ} \mathrm{C}$ and lower operating pressure (13.7 MPa). The unsaturated components, such as linoleic and oleic acids were extracted at higher pressures of 27.6 and $34.5 \mathrm{MPa}$, respectively. The fatty acids composition of the extracted oil analyzed using gas chromatography-mass spectrometry (GC/MS) includes caprylic, capric, lauric, myristic, palmitic, margaric, stearic, oleic, linoleic, linolenic, arachidic and gadoleic acids.
\end{abstract}

Keyword: Supercritical-CO2; Sterilization; Extraction; Fatty acids; Residual-palm-oil 